\title{
STRENGTH ANALYSIS OF POLYMER CONICAL GEAR WHEEL MADE WITH 3D PRINTING TECHNIQUE
}

\author{
Szczepan Śpiewak \\ Czestochowa University of Technology \\ Faculty of Mechanical Engineering and Computer Science \\ Dabrowskiego Street 73, 42-201 Czestochowa, Poland \\ tel.: +4834 3250629, fax: +48343250647 \\ e-mail:szczepan_spiewak@poczta.onet.pl \\ Jan Awrejcewicz \\ Lodz University of Technology \\ Department of Automation Biomechanics and Mechatronics and Technology \\ Stefanowskiego Street 1/15, 90-924 Lodz, Poland \\ tel.: +48426312225 \\ e-mail:awrejcew@p.lodz.pl
}

\begin{abstract}
The article deals with the problem of designing conical gears with a curved line contour. The contour of the tooth flank is described by means of a helix and involutions. In the work, a conical gear designed to drive of the lower limb rehabilitation exoskeleton has analysed. Parameters of the conical gearbox have been adapted to design requirements of the exoskeleton. Gear wheels were made with ABS material using 3D printing technique. The article presents the results of strength calculations obtained using the method classical design of the gear wheals described in the norm ISO 6336-1996. In the strength calculations, bending and contact stresses were taken into account. Creating the contour of gears was aided through the gearbox wizard available in Inventor program. The work contains the results of a static tensile test of the material from which the gear wheels were made. In experimental and numerical studies, the orthotropy of the material used was taken into account. The orthogonal values of the Young's modulus, the Poisson's ratio and the Kirchhoff's modulus were determined. The publication also includes partial results of fatigue tests in the area of normal stresses. In the research used to finite element method (FEM), determine of internal loads in the gear. A structure of the FEM model is described in detail. Maximum values of contact pressures determined by use to FEM models have been compared with the results obtained on the basis of Hertz's formulas. The article presents basic geometrical and strength parameters of the designed gear. The work demonstrates the validity of the material models used. Limitations in the application of the classic method of calculating conical gears made of orthotropic materials have been indicated. The results of analytical and numerical calculations are presented in tabular and graphical form.
\end{abstract}

Keywords: Exoskeleton, strength analysis, finite element method (FEM), material model of acrylonitrile-co-butadieneco-styrene, conical gears

\section{Introduction}

One of the devices that at certain stages of human rehabilitation can significantly aided the work of a physiotherapist is a rehabilitation exoskeleton. In the publication [3], ten different design solutions of exoskeletons used for rehabilitation or for improve the motor efficiency of the human knee joint, were listed. An example of a typical exoskeleton, which provides motion stability by means of an integrated power train and fastening elements of the limb, has been presented in [9]. In order to increase the availability of exoskeletons for many people that requiring rehabilitation, costs of a manufacture such a system should be small as possible. This can be ensured mainly 
through use of cheap manufacturing techniques and cheap blanks. Set of the cost includes mainly prototyping, testing and developing improvements. In prototyping, it is common to use a rapid prototyping technique based on 3D printing to perform of parts selected. This applies especially to those parts whose shape is difficult to obtain, for example, by machining methods or moulding. The elements made with the help of the 3D printing technique can be permanently introduced into the assembly process in the product finished. The condition is to ensure the required durability.

A variety of calculation methods adapted to the relevant parts of machines can be used to evaluate the functional properties and, in particular, the strength properties of the elements made with the 3D printing technique. At the stage of preliminary calculations, simplified analytical formulas are often used, and numerical methods are used at the stage of improvement or optimization. At the implementation stage, however, it is good practice to carry out the calculations or tests indicated by the norms.

This article concerns the strength analysis of a conical gear. This analysis boils down to a comparison of the results of calculations obtained on the basis of guidelines for norms describing toothed wheels, models made based on finite element method (FEM) and simplified analytical formulas in the field of materials strength. In the developed exoskeleton design, it was decided to use a drive system with an angular gear for transferring the drive between the electric motor and the rotary movement member in the joints. Due to the availability of a 3D printer, it was decided to develop a conical gear that will meet the strength requirements and a $3 \mathrm{D}$ printing technique could be made. The material used for this process is acrylonitrile-co-butadiene-co-styrene (ABS).

\section{Conical gear in the exoskeleton}

\subsection{Position of the gear in the exoskeleton - design assumptions}

In the developed design solution of the rehabilitation exoskeleton, the following assembles marked in Fig. 1 can be distinguished: ankle joint assembly (I), knee joint assembly (II), hip joint assembly (III), pelvis module assembly (IV), spine support assembly (V), spring connectors (VI) and driving unit (VII). The basic task of individual assemblies is to ensure the patient's movement stability. The patient is connected to the exoskeleton using the elastic belts that are in the metatarsus module (1), contoured shank mount (2), contoured thigh mount (3) and mainstay (4). The task of team VI is to ensure compensation of the trajectory of joint movement, and in particular of the knee joint, which does not have a fixed axis of rotation. An additional task of this element was to reduce the axial loads of the exoskeleton caused during the impact of the foot against the ground. The drive assembly VII has been unified and applied in all articulated joints, where the rotary motion has been assumed. The output parameters of the drive system such as nominal torque $T=32 \mathrm{Nm}$ and the required speed range $n=100 \mathrm{rpm}$ were determined based on work [5]. The driving unit is presented in detail in Fig. 2. The drive is transmitted from the stepper motor (1) via the planetary gear 2 with the ratio $i=40$ to the drive wheel (3) and the driven wheel (4). The housing of the planetary gear is attached to the exoskeleton using the clamp (5) marked in Fig. 1. The conical wheels are mounted on shafts and connected by means of key joints. Due to better strength properties, it was decided to use conical gear wheels with a curved tooth profile with the following parameters: transverse module $m=5 \mathrm{~mm}$, number of teeth $z=14$, the length of the tooth's line $b=20 \mathrm{~mm}$, semi-angle of the pitch conic $\theta=45^{\circ}$, pressure angle $\alpha=20^{\circ}$, helix angle $\beta=34^{\circ}$, tooth height coefficient $y=1$, profile shift coefficient $x=0$.

Based on the appropriate geometrical relations [4], a structural model of the full meshing contour of the analysed gears wheal was created by using the Inventor system (Fig. 2). Then a 3D print out and hardness measurement of the side of the tooth were made. This hardness is on the Brinell scale amount to $250 \mathrm{HB}$. In order to be able to evaluate the mechanical properties of the gears, the strength parameters of the ABS material have to be determined. 


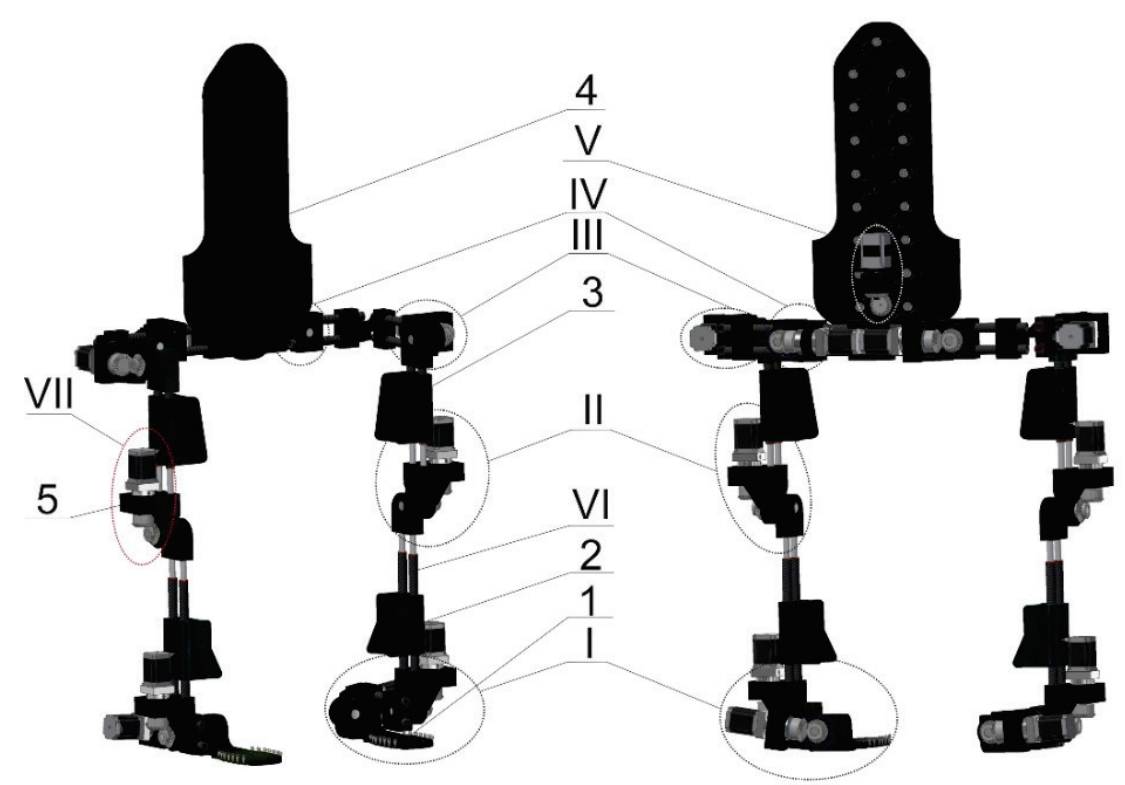

Fig. 1. The exoskeleton structural model

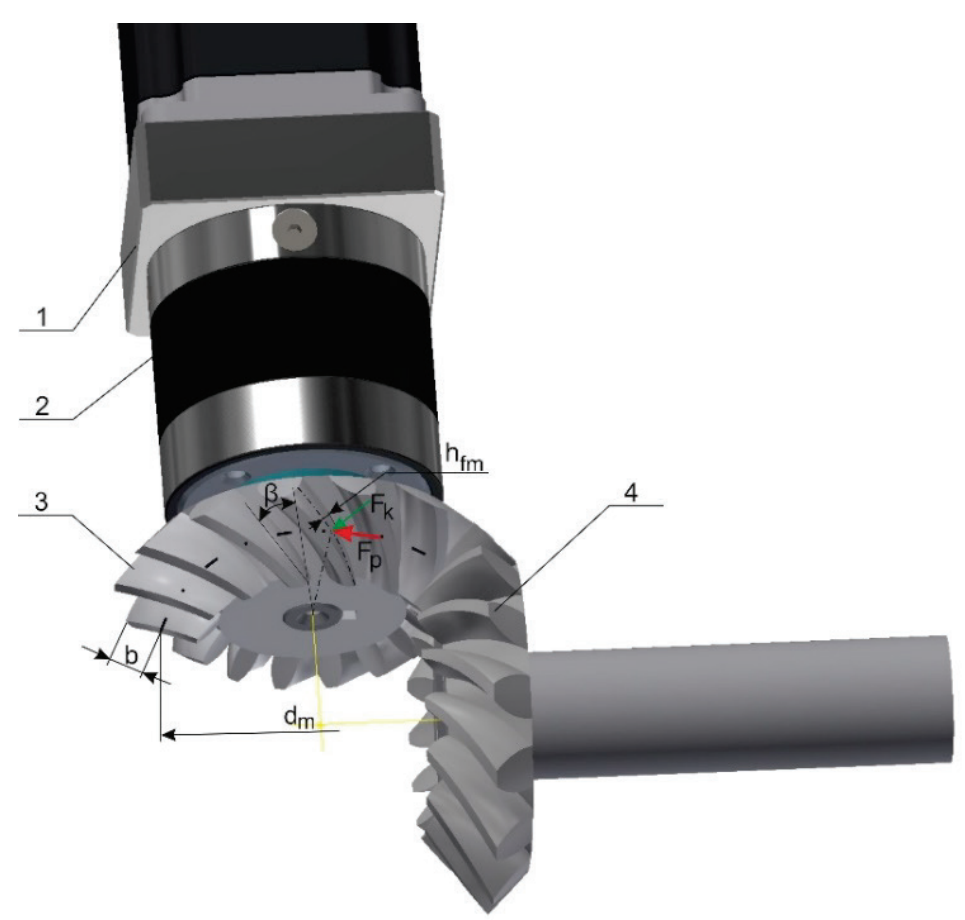

Fig. 2. The driving unit with conical gear

As this material indicate orthotropic properties resulting from the direction of applying successive layers in the printing process [7], in order to determine material parameters, a static tensile test and a static twisting test of cylindrical samples were carried out. The samples were made in two orientations (horizontal and vertical) with respect to the main plane of the print out $a b$. In the printing process, subsequent layers are applied to the plane $\boldsymbol{a b}$ along the $\boldsymbol{c}$ axis. Based on the research it is obtained following parameters of orthotropic material models: Young's modulus $E_{a}=1026 \mathrm{MPa}, E_{b}=E_{c}=115 \mathrm{MPa}$, Poisson's ratio $v_{b a}=0.49, v_{c b}=v_{c a}=0.198$, Kirchhoff module $G_{b a}=405 \mathrm{MPa}, G_{c b}=G_{c a}=425 \mathrm{MPa}$ and tensile strength $R_{a}=26 \mathrm{MPa}, R_{b}=R_{c}=20 \mathrm{MPa}$.

Based on the adopted geometric, kinematic and material assumptions, the calculations were started. Strength calculations of gears boils down to the determination of bending stress and contact pressure located on the side surface of the tooth. 


\subsection{Calculations of the gear according to PN-ISO 6336}

One of the basic standards (but currently withdrawn) based on which it is recommended to conduct strength calculations of gears is the norm PN-ISO-6336 [8]. These norms give calculation formulas for tooth wheels with spur gears. However, the geometrical dimensions of radii of conical wheels gear comes down to the so-called replacement dimensions as dimensions of cylindrical wheels with radii equal to those a slant height the front cones of a conical gear [4]. In addition, it is assumed that the resultant forces act in the middle of the length of the tooth line $b$ measured on the pitch cone that is described diameter $d_{m}=55.858 \mathrm{~mm}$ (Fig. 2). It should be noted that when determining the circumferential force $F_{I S O}$ according to the norm $[4,8]$ a replacement diameter are taken into account $d_{z}=d_{m} / \cos \theta$, hence $F_{I S O}=2 T / d_{z}$. Next, a transverse contact ratio was determined $\varepsilon_{\alpha}=1.6$ and a face contact ratio $\varepsilon_{\beta}=1.6$.

The main formula for determining the bending stress at the base of the tooth according to the norm has the form $[4,8]$ :

$$
\sigma_{g I S O}=\frac{F_{I S O} K_{A} K_{V} K_{F \beta} K_{F \alpha} Y_{F S} Y_{\varepsilon} Y_{\beta}}{0.85 b m_{m t}}
$$

and a formula for determining contact pressure $[4,8]$ :

$$
p_{I S O}=Z_{H} Z_{E} Z_{\varepsilon} Z_{\beta} \sqrt{\frac{F_{I S O}}{0.85 b d_{z}} \frac{i}{i+1}} \sqrt{K_{A} K_{V} K_{H \beta} K_{H \alpha}} .
$$

Individual symbols from formula (1) and (2) denotes:

$F_{I S O}=810 \mathrm{~N}$ - circumferential force related to the replacement diameter

$K_{A}=1 \quad-$ application coefficient,

$K_{V}=1.017-$ coefficient of dynamic surpluses,

$K_{F \beta}=1.875-$ coefficient of load unevenness along the tooth line (for bending stress)

$K_{F \alpha}=1.392-$ coefficient of unevenness of the tooth load in the frontal cross-section (for bending stress),

$Y_{F S}=4.4 \quad$ - tooth shape factor and notch shape in the tooth base,

$Y_{\varepsilon}=0.719-$ coefficient of transverse contact ratio,

$Y_{\beta}=0.711-$ coefficient of helix angle,

$m_{m t}=3.9 \quad-$ transverse module in medium section,

$Z_{H}=2.271 \quad-$ the shape factor of the tooth surface,

$Z_{E}=14.659$ - coefficient of elasticity (for $E_{a}, v_{b a}$ ),

$Z_{E}=13.59-$ coefficient of elasticity (for $E_{b}=E_{c}, v_{c b}=v_{c a}$ ),

$Z_{\varepsilon}=0.791-$ coefficient of transverse contact ratio (for contact pressure),

$Z_{\beta}=0.911-$ coefficient of helix angle (for contact pressure),

$K_{H \beta}=1.875-$ coefficient of load unevenness along the tooth line (for contact pressure),

$K_{H \alpha}=1.6-$ coefficient of unevenness of the tooth load in the frontal cross-section (for contact pressure).

Considering that as a result of the $3 \mathrm{D}$ printing process, individual teeth have different of a directional structure, so in the calculation, the extreme values of material parameters that describe orthotropy should be taken into account. Using the formulas (1) and (2) and material model parameters, the values of bending stress and contact pressure were calculated and shown in Tab. 1.

Tab. 1. Stress values obtained based on the ISO method (formula 1 and 2)

\begin{tabular}{|l|c|c|}
\hline \multicolumn{1}{|c|}{ Material model } & \multicolumn{2}{|c|}{ Type of stress [MPa] } \\
\hline$E_{a}=1026, v_{c b}=v_{c a}=0.49$ & $\sigma_{g I S O}=71.3$ & $p_{I S O}=46.0$ \\
\hline$E_{b}=E_{c}=1115, v_{c b}=v_{c a}=0.198$ & $\sigma_{g I S O}=71.3$ & $p_{I S O}=42.6$ \\
\hline
\end{tabular}




\subsection{FEM model of the conical gear}

Using the structural model of the conical gear in the ADINA program [1] discretization with finite elements type of 3D-solid [2] has been made (Fig. 3).

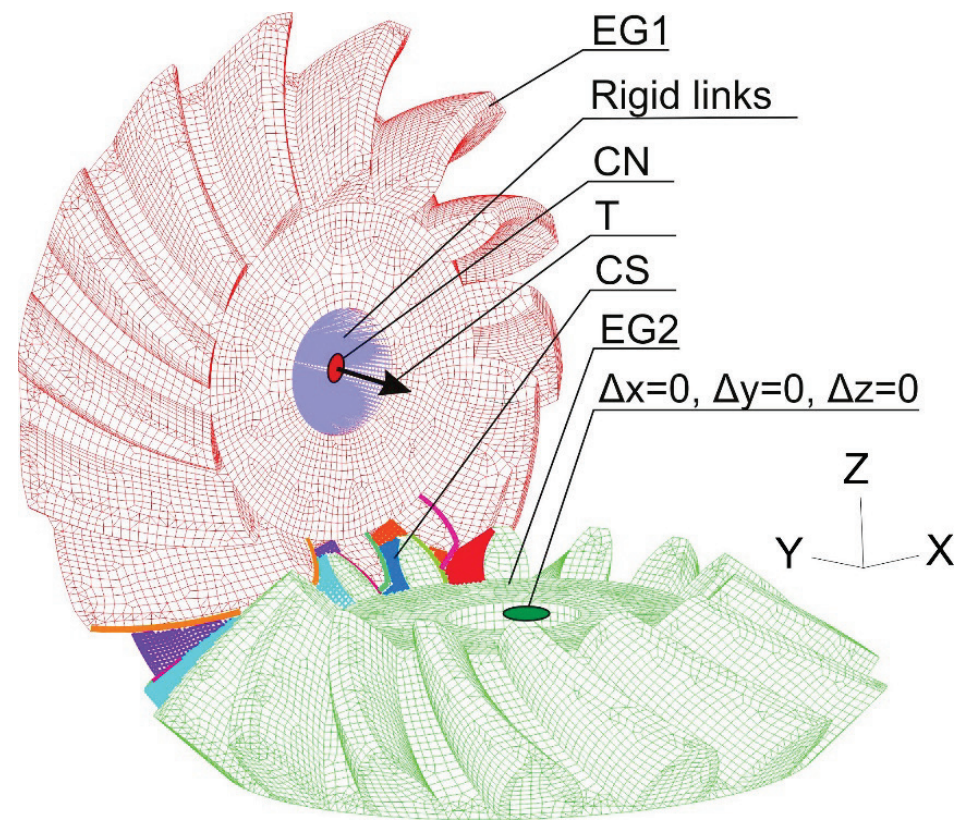

Fig. 3. FEM-mesh of the model conical gear

In order to implement the orthotropic material model, two groups of finite elements were identified, respectively representing the EG1 drive wheel and the EG2 driven wheel. Thus, they are based on a global coordinate system $\boldsymbol{x y z}$ and the $\boldsymbol{x}$-axis for the groups EG1 and EG2 represents the orthotropy axis $\boldsymbol{a}$, whereas the orthotropic $\boldsymbol{c}$ axis correspond for the $\boldsymbol{y}$-axis of the EG1 group of and $\boldsymbol{z}$-axis of the EG2 group. Between the nodes representing the lateral surfaces $\boldsymbol{C S}$ of the teeth in the model, contact conditions have been defined with taken into account a penetration $[1,2]$ and a sliding friction. The friction coefficient $\mu=0.1$ has been defined in the contact model. The boundary conditions of the displacements were defined on nodes representing the hole of the driven gear. The load was defined as the torque vector $T=32 \mathrm{Nm}$ that is hooked at the central $\boldsymbol{C N}$ node of the drive wheel bore. All nodes representing the drive wheel bore were connected to the central node by means of rigid links. Based on the defined FEM model, a static analysis was carried out. Distribution of the bending stress and the contact pressure located on the lateral surfaces of teeth is shown in the Fig. 4 and 5.

It can be seen that the maximum bending stress is located at the base of the tooth and amount to $\sigma_{g F E M}=25 \mathrm{MPa}$. Whereas, the contact pressure has been determined on a contact line of the tooth containing the diameter $d_{m}$ (Fig. 2). The maximum value of contact pressure in the central zone of the contact line amounts to $\boldsymbol{p}_{F E M}=\mathbf{3 0} \mathbf{M P a}$.

\subsection{Simplified method of the stress calculation}

Taking into account the differences concerning values of the bending stress and the contact pressures of teeth, it has been determined according to the norm [8] and FEM. It was found that simplified formula should be used. The following Hertz [6] formulas were used to calculate the maximum contact pressure $p_{H}$ :

$$
p_{H}=\frac{1.5 F_{k}}{\pi a_{e} b_{e}}
$$




$$
\begin{gathered}
F_{k}=\frac{F_{p}}{\varepsilon_{\alpha}} \frac{\cos \beta}{\cos \alpha}, \\
F_{p}=\frac{2 T}{d_{m}}, \\
a_{e}=a_{H} \sqrt[3]{\frac{3 F_{K}}{E_{o} \sum \rho}}, \\
b_{e}=b_{H} \sqrt[3]{\frac{3 F_{K}}{E_{o} \sum \rho}} \\
\sum \rho= \pm \frac{1}{R_{A 1}} \pm \frac{1}{R_{A 2}} \pm \frac{1}{R_{B 1}} \pm \frac{1}{R_{B 2}} .
\end{gathered}
$$

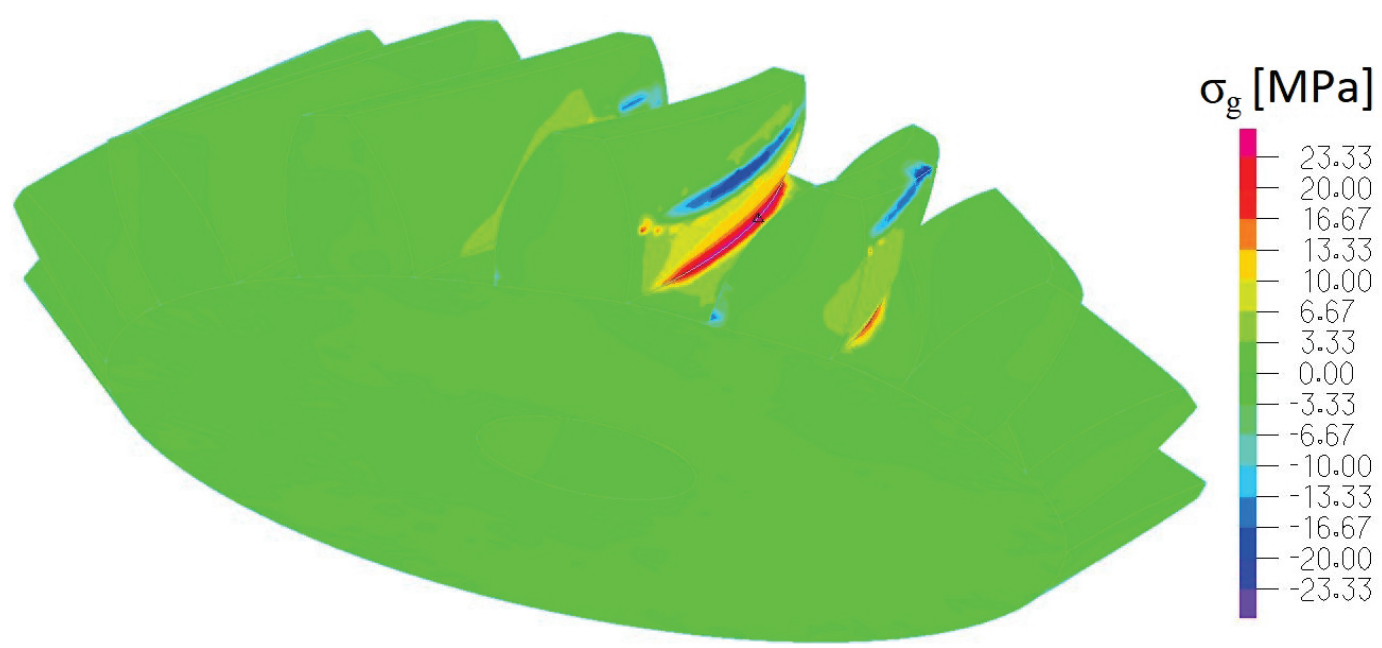

Fig. 4. Distribution of the bending stress at the meshing place of gear wheels

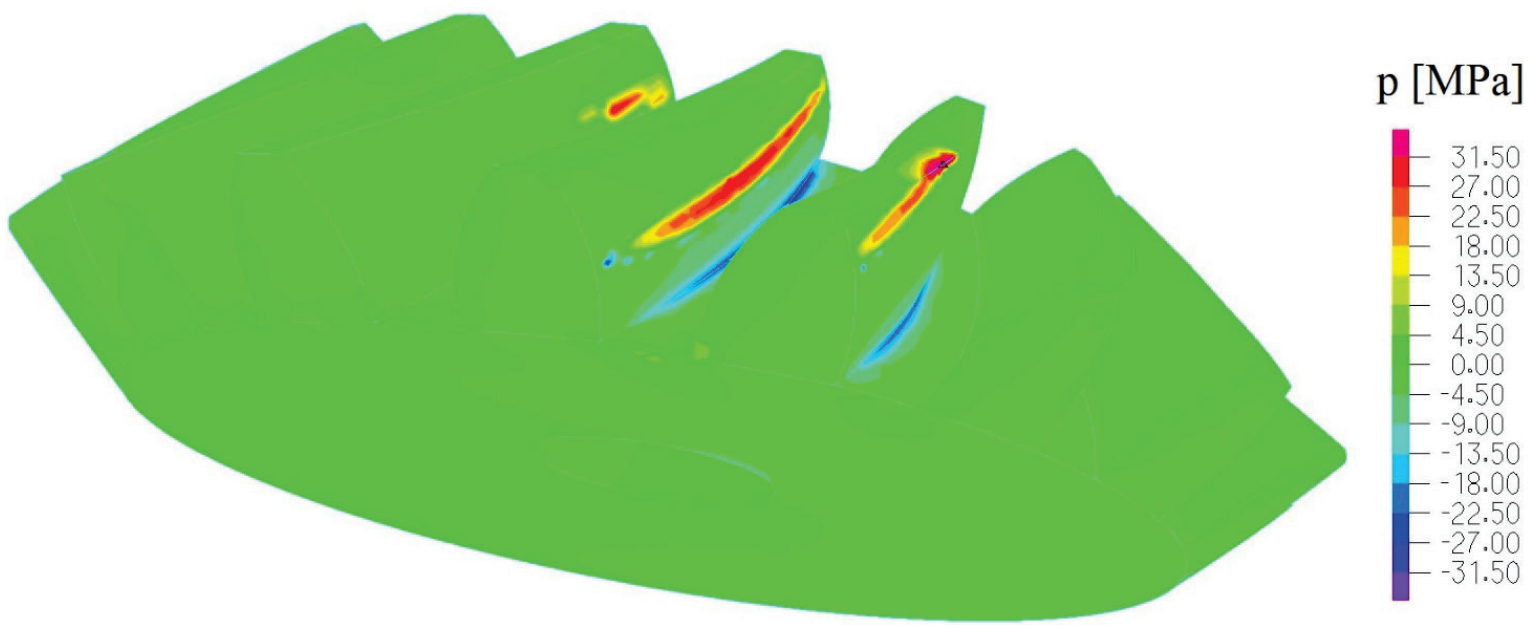

Fig. 5. Distribution of the contact pressure at the meshing place of gear wheels

Individual symbols from formulas 3-8 denotes:

$F_{k}=631.6 \mathrm{~N}-$ orthogonal force at the central point of tooth contact,

$F_{p}=1146 \mathrm{~N}$ - circumferential force,

$a_{e}, b_{e}$ - rays of the ellipsoid in the contact zone,

$a_{H}, b_{H}$ - curvature parameters dependent on $H$ :

$$
\mathrm{H}=\frac{\left(\frac{1}{\mathrm{R}_{\mathrm{A} 1}}-\frac{1}{\mathrm{R}_{\mathrm{A} 2}}\right)+\left(\frac{1}{\mathrm{R}_{\mathrm{B} 1}}-\frac{1}{\mathrm{R}_{\mathrm{B} 2}}\right)}{\sum \rho}
$$


$R_{A 1}=17.23 \mathrm{~mm}, R_{A 2}=36.31 \mathrm{~mm} \quad$ - the radii of the curvature of the body A measured in two perpendicular planes 1 and 2 ,

$R_{B 1}=14.19 \mathrm{~mm}, R_{B 2}=41.68 \mathrm{~mm} \quad$ - the radii of the curvature of the body B measured in two perpendicular planes 1 and 2 ,

$E_{o}$ - a replacement modulus of elasticity at the contact of two bodies made of different materials,

* - signs in formulas 8 and 9: (+) for convex curves, (-) for concave curves defined with respect to the contact zone.

Using the geometric model of the conical gear wheels (Fig. 2), the radii $R_{A 1}, R_{A 2}, R_{B 1}, R_{B 2}$ of curvatures crossing in the point of applying normal force $F_{k}$ to the surface of the contact zone were determined. The material model for the directions of orthotropy $\boldsymbol{b}$ and $\boldsymbol{c}$, which indicate lower tensile strength $\left(R_{b}=R_{c}=20 \mathrm{MPa}\right)$, was adopted for the calculations. The value of maximum contact pressures in the considered contact zone at the defined load amount to $\boldsymbol{p}_{\boldsymbol{H}}=\mathbf{3 4 . 2} \mathrm{MPa}$.

To calculate bending stress, it was assumed that the cross-section subject to bending has the shape of a rectangle with dimensions $S \times b$. $S$ is the width of the tooth base measured in the middle of the length of tooth line $b$ on the root diameter.

From the above, dependencies are obtained:

$$
\begin{gathered}
\sigma_{\mathrm{g}}=\frac{6 \mathrm{~F}_{\mathrm{p}} \mathrm{h}_{\mathrm{fm}}}{\varepsilon_{\alpha} \mathrm{b}\left(\frac{\mathrm{s}}{\cos \beta}\right)^{2}}, \\
\mathrm{~S}=\left(\mathrm{d}_{\mathrm{f}}-\frac{\mathrm{b} \sin \left(\theta_{\mathrm{f}}\right.}{\cos \left(\theta_{\mathrm{hf}}\right.}\right) \sin \left(\frac{2 \pi}{4 \mathrm{z}}\right) .
\end{gathered}
$$

Individual symbols from formula (10) and (11) denote:

$h_{f m}=4.788 \mathrm{~mm}$ - tooth root height related to diameter $d_{m}$,

$d_{f}=61.515 \mathrm{~mm}-$ root diameter,

$z=14$ - number of teeth,

$\theta_{f}=38^{\circ}-$ angle between the axis of rotation of the gear wheel and the slant height of the cone with the base diameter equal to $d_{f}$,

$\theta_{f}=7^{\circ} \quad$ angle between the slant height of the cones (with a common vertex) with bases diameters $d_{f}$ and $d$ (reference diameter of the gear wheel).

Based on the formula (10) and the set load, the calculated value of bending stress amount to $\sigma_{g}=26.3$ MPa.

\section{Comparison of results - summary}

A set of the results obtained for the presented methods is shown in the Tab. 2.

Tab. 2. List of values of the stress calculated for the presented methods

\begin{tabular}{|c|c|c|c|}
\hline \multirow{2}{*}{ Method } & \multicolumn{3}{|c|}{ Type of stress [MPa] } \\
\cline { 2 - 4 } & Bending & \multicolumn{2}{|c|}{ Contact pressure } \\
\hline ISO & 71 & 46.0 & 42.6 \\
\hline FEM & 25 & \multicolumn{2}{|c|}{30} \\
\hline Simplified & 26.3 & \multicolumn{2}{|c|}{34.2} \\
\hline
\end{tabular}

Based on the results presented, it can be concluded that the highest values of stress were obtained using the ISO method and the smallest for the FEM simulations. Discrepancies in these results are at $280 \%$ for bending stress and $153 \%$ for contact pressure. It can be concluded that the ISO method gives highly overestimated values that include the safety factor. Taking into account, the proposed simplified method, it can be stated that it gives a good result at the lowest calculation 
time. Regarding to the obtained values of bending stress, it can be stated that for the assumed load and the level of the tensile strength of the ABS material $(R a=26 \mathrm{MPa})$ - the performed gear can be used to only prototype tests of exoskeleton. In the further stage of the research, fatigue tests of the material in a range axial stress and contact presser are expected. The results of these tests will allow estimating the durability of the analysed conical gear.

\section{Acknowledgements}

Work done in the scope of the grant OPUS 9, No. 2015/17/B/ST8/01700.

Mechanical tests were performed on Zwick Biaxial 4 x EZ002 (4 x $2 \mathrm{kN})$ and Zwick LTM10/Z010TE installed at Mechanical Engineering Faculty, Gdansk University of Technology (No. 6572/IA/SP/2016, Ministry of Science and Higher Education).

\section{References}

[1] ADINA, Theory and Modeling Guide. Volume 1, ADINA R\&D, Inc. Watertown 2007.

[2] Bathe, K. J., Finite Element Procedures, Prentice-Hall, Inc. Simon \& Schuster / A Viacom Company Upper Saddle River, New Jersey 1996.

[3] Chen, B., Zi, B., Wang, Z., Qin, L, Liao, W., Knee exoskeletons for gait rehabilitation and human performance augmentation: A state-of-the-art, Mechanism and Machine Theory, Vol. 134, pp. 499-511, 2019.

[4] Dziurski, A., Kania, L., Kasprzycki, A., Mazanek, E., Ziora, J., Przykłady obliczeń z podstaw konstrukcji maszyn, WNT, Warszawa 2019.

[5] Grimmer, M., Quinlivan, B. T., Lee, S., Malcolm, P., Rossi, D. M., Siviy, C., Walsh, C., Comparison of the human-exosuit interaction using ankle moment and ankle positive power inspired walking assistance, Journal of Biomechanics, Vol. 83, pp. 76-84, 2019.

[6] Haris, T. A., Kotzalas, M. N., Essential Concepts of Bearing Technology. Rolling Bearing Analysis, $5^{\text {th }}$ ed. CRC Press Taylor \& Francis Group, Boca Raton, London, New York 2007.

[7] Zhang, H., Cai, L., Golub, M., Zhang, Y., Yang, X., Schlarman, K., Zhang, J., Tensile, Creep, and Fatigue Behaviors of 3D-Printed Acrylonitrile Butadiene Styrene, Journal of Materials Engineering and Performance, Vol. 27 (1), pp. 57-62, 2018.

[8] PN-ISO 6336-1:2000, Przekładnie walcowe. Obliczanie nośności kół; 6336-2:2000 Wytrzymałość zęba na zmęczenie stykowe (pitting); 6336-3:2001, Wytrzymatość zęba na zginanie.

[9] Yatsun, A., Jatsun, S., Modeling quasi-static gait of a personwearing lower limb exoskeleton, Springer Nature Switzerland AG, Proceedings of the 4th International Conference on Industrial Engineering Lecture Notes in Mechanical Engineering, pp. 565-575, 2019.

Manuscript received 07 June 2019; approved for printing 19 September 2019 